\title{
Analisa Maturity Level Pencapaian Optimasi Layanan TI Perguruan Tinggi
}

\author{
Friden Elefri Neno* ${ }^{*}$, Kusrini ${ }^{2}$, Henderi $^{3}$ \\ ${ }^{1,2,3}$ Program Magister Teknik Informatika Universitas AMIKOM Yogyakarta \\ E-mail: $\underline{\text { "1 nenofriden.e@gmail.com }},{ }^{2}$ kusrini@ amikom.ac.id, ${ }^{3}$ henderi@mail.ugm.ac.id
}

\begin{abstract}
Abstrak
Teknologi informasi (TI) merupakan suatu kebutuhan yang sangat penting bagi semua aktivitas kegiatan karena di percaya dapat meningkatkan efektifitas dan efesiensi proses pekerjaan, Untuk mencapai hal tersebut di perlukan optimasi pelayan TI yang baik dan benar agar keberadaan TI dapat menunjang kesuksesan pekerjaan dalam instansi swasta, pemerintahan dan pendidikan dalam mencapai tujuannya. Oleh Karena itu Stimikom Stella Maris Sumba ingin mengetahui kesuksesan Keberadaan teknologi informasi yang mendukung proses optimasi pelayanan kepada segenap civitas akademika pada sebuah perguruan tinggi yang merupakan tuntutan yang tidak bisa dihindari, Keberadaan sistem informasi akademik perguruan tinggi yang berfungsi untuk melayani proses akademik mahasiswa dan dosen merupakan suatu keharusan. Pengukuran dari tujuan sistem informasi adalah untuk memberikan kontribusi terhadap terknologi informasi terhadap kinerja bisnis pada perguruan Tinggi Stimikom Stella Maris Sumba untuk mengukur seberapa jauh keselarasan antara proses bisnis, maka perlu diperlukan audit sistem informasi yang diperlukan sebuah standar, maka standar yang digunakan adalah COBIT 4.1 dengan hasil akhir yang diperoleh pada nilai tingkat kematangan maturity level optimasi pelayanan TI berada pada nilai 2.51 dengan keterangan Repeatable but intuitive.
\end{abstract}

Kata Kunci-3-5 Maturity Level, Optimasi Layanan

\begin{abstract}
Information technology (IT) is a very important requirement for all activity activities because it is believed to increase the effectiveness and efficiency of the work process. To achieve this, it is necessary to optimize the IT servants' good and correct so that the existence of IT can support the success of work in private agencies. government and education in achieving its goals. Therefore Stella Maris SimStimikom wants to know the success of the existence of information technology that supports the process of optimization of service to all academics in a university which is an unavoidable demand, the existence of a college academic information system that serves to serve the academic process of students and lecturers is a must. Measurements of the purpose of information systems is to contribute to information technology on business performance at Stella Maris Sumba Stimicom College to measure the extent of alignment between business processes, it is necessary to need an information system audit that requires a standard, then the standard used is COBIT 4.1 with the final result obtained at the maturity level value of the IT service level is at 2.51 with the description Repeatable but intuitive.
\end{abstract}

Keywords-3-5 Service Optimization, Maturity Level 


\section{PENDAHULUAN}

Perkembangan teknologi dalam dunia pendidikan telah mengalami peningkatan yang cukup signifikan. Karena itu pada saat ini hampir tidak ada lagi masyarakat yang tidak mengenal pendidikan, meskipun berbeda dalam jenjang yang mampu ditempuhnya. Pemerintah telah memberikan perhatian untuk peningkatan mutu pendidikan tinggi di Indonesia. Dengan terbitnya UU Nomor 12 Tahun 2012 tentang Pendidikan Tinggi.

Kualitas perguruan tinggi tidak terlepas dari layanan akademik maka perlu diterapkan Teknologi informasi sebagai kebutuhan yang diperlukan untuk mencapai efektifitas dan efisiensi kerja dalam perkembangan teknologi saat ini. Perkembangan teknologi akan mendorong pengolahan data yang sistem tradisional ke sistem teknologi informasi untuk mencapai optimasi dengan yang diharapkan

Lembaga pendidikan Stimikom Stella Maris Sumba telah menggunakan teknologi informasi dalam menunjang kegiatan pelayanan akademik yang sejauh mana atau seberapa besar penerapan teknologi informasi untuk mencapai optimasi layananan pada bidang akademik kemahasiswaan (BAAK) yang belum diketahui atau belum terukur dengan baik dengan pemanfaatan teknologi informasi dapat mengetahui kebutuhan dan kendala yang mempengaruhi optimasi layanan sehingga dari pengelolah manajemen mengambil keputusan sesuai dengan rekomendasi untuk memperbaiki agar menunjang proses lembaga sesuai dengan visi dan misi perguruan tinggi.

Untuk mengetahui berapa maturity level pencapaian optimasi layanan teknologi informasi pada perguruan tinggi Stimikom Stella Maris Sumba yang valid dan realabledibutuhkan alat bantu yaitu cobit 4.1 karena merupkan kerangka kerja yang memberikan gambaran yang detail dan strategis dalam kontrol pengaturan proses teknologi informasi yang mendukung keselarasan startegis bisnis dan tujuan teknologi informasi. Dengan menentukan domain, tujuan bisnis dan proses yang terdapat 4 (empat) tujuan bisnis meliputi Perolehan dan pemeliharaan sistem aplikasi yang standar dan terintegrasi, Perolehan dan pemeliharaan infrastruktur teknologi informasi yang strandar dan terintegrasi, Jaminan akan kepuasan yang saling menguntungkan dengan pihak ketiga dan Peningkatan terhadap efisiensi biaya teknologi informasi dan kontribusinya terhadap keuntungan bisnis dengan proses PO2,PO5,AI2AI3,AI5,DS2,DS6

Beberapa penelitian terlebih dahulu yang dilakukan sebelumnya dan menjadi referensi penelitian adalah:Penelitian yang dilakukan oleh Wire Bagye tentang Analisis Tingkat KematanganSistemInformasiAkademikMenggunakan Framework COBIT 4.1 (StudiKasus: STMIK Lombok) tujuan penelitian ini adalah untuk mengetahui tingkat kepuasan mahasiswa sebagai pelanggan dengan alat ukur framework cobit 4.Ipenelitian terebut bertujuan untuk memperoleh nilai kematangan tata kelola serta tujuan bisnis yang digunakan adalah Improve customer orientation and service dengan proses domain PO.AI,DSdengan hasil penelitian menunjukan bahwa perhitungan tingkat kematangandiperoleh dari setiap proses dalam control objective tidak menghitung nilai rata-rata dari tingkat kematangan untuk semuacontrol objective[2] dan penelitian selanjutnya menghasilkan nilai maturity level rata-rata dari kondisi sekarang (As-Is) dan kondisi yang diharapkan ( $T o$ Be) serta nilai GAP

Penelitian yang dilakukan oleh Awalludiyah Ambarwati tentangAnalisis Maturity Level Business Goals 8 Menggunakan COBIT Pada PT APLIN.Penelitian ini bertujuan memberikan layanan untuk memenuhi kebutuhan pelanggan dan mengetahui maturity level dengan framework cobit 4.1 pada empat proses teknologi informasi meliputi PO3 (menentukan arahan teknologi),AI5 (pengadaan sumber daya TI),DS2 (mengelolah layanan pihak ke tiga) dan DS6 (mengidentifikasikan dan mengalokasikan biaya). Hasil penelitian menunjukan bahwa menghasilkan nilai maturity level serta memberikan rekomendasi untuk perbaikan pembuatan startegis TI dan SOP untuk pembagian tugas karyawan [3]. Penelitian selanjutnya menghasilkan nilai maturity level rata-rata dari kondisi sekarang $(A s-I s)$ dan kondisi yang diharapkan (To Be) serta nilai $G A P$

Penelitian yang dilakukan oleh Khairan Marzuki tentang Audit Tata Kelola Teknologi Informasi Menggunakan Cobit 4.1 Domain Monitoring Evaluasi Pada Perguruan Tinggi Swasta 
penelitian ini dengan bertujuan berupa tingkat kematangan Sistem Informasi Akademik yang mencerminkan kondisi tata kelola saat ini dan tingkat kematangan yang diharapkan di kampus STMIK Bumigora Mataram dengan mengacu pada maturity level yang disediakan kerangka kerja Cobit 4.1. Domain yang digunakan Monitoring and Evaluation [4]. Penelitian selanjutnya pencapaian optimasi layanan TI pada perguruan tinggi untuk analisa maturity level saat ini asis) dan yang diharapkan (to-be) dengan domain PO,AI,DS

Berdasarkan hasil Penelitian yang dilakukan oleh Wire Bagye, Awalludiyah Ambarwati dan Khairan Marzuki yang sudah diuraikan diatas,penelitian selanjutnyatentang Analisa Maturity Level Pencapaian optimasi layanan TI tersebut dapat dilakukan dengan menggunakan salah satu dari beberapa framework yang ada, di antaranya adalah COBIT,ISO/IEC 17799:2005 dan IT-IL[1]. Disini penulis akan menggunakan framework COBIT (Control Objectives For Information And Realted Technology) sebagai acuan dalam mengevaluasi TI pemilihan COBIT 4.1 yang dilihat dari cakupan yang lebih luas, detail dan terperinci terkait pengawasan dan pengelolaan teknologi dari framework-framework yang ada.Hasil akhir dari penelitian ini menjadi dasar untuk memberikan rekomendasi kepada pihak manajemen untuk pembenahan kekurang sesuai dengan rekomendasi agar pencapaian optimis pelayanan sesuai dengan visi dan misi perguruan tinggi.

\section{METODE PENELITIAN}

\subsection{Metodologi Pengumpulan data}

Beberapa tahapan yang digunakan dalam pengumpulan data

1. Identifikasi masalah

2. Metode Pengumpulan data, Jenis pengumpulan data terbagi dua jenis
a. Primer
Data dihimpun langsng di obyek penelitian melputi wawancara dan penelitian
b. Data Sekunder
Data yang diperoleh berupa referensi yang berkaitan dengan masalah penelitian

\subsection{Metode Analisa Data}

Setelah data-data terkumpul tahap selanjut pengolahan data dilakukan secara berjenjang
a. Nilai Maturity level
b. Nilai Kesenjangan
c. Rekomendasi 
Pada gambar 1. dibahwa ini terdapat beberapa tahapan dalam melakaukan penelitian

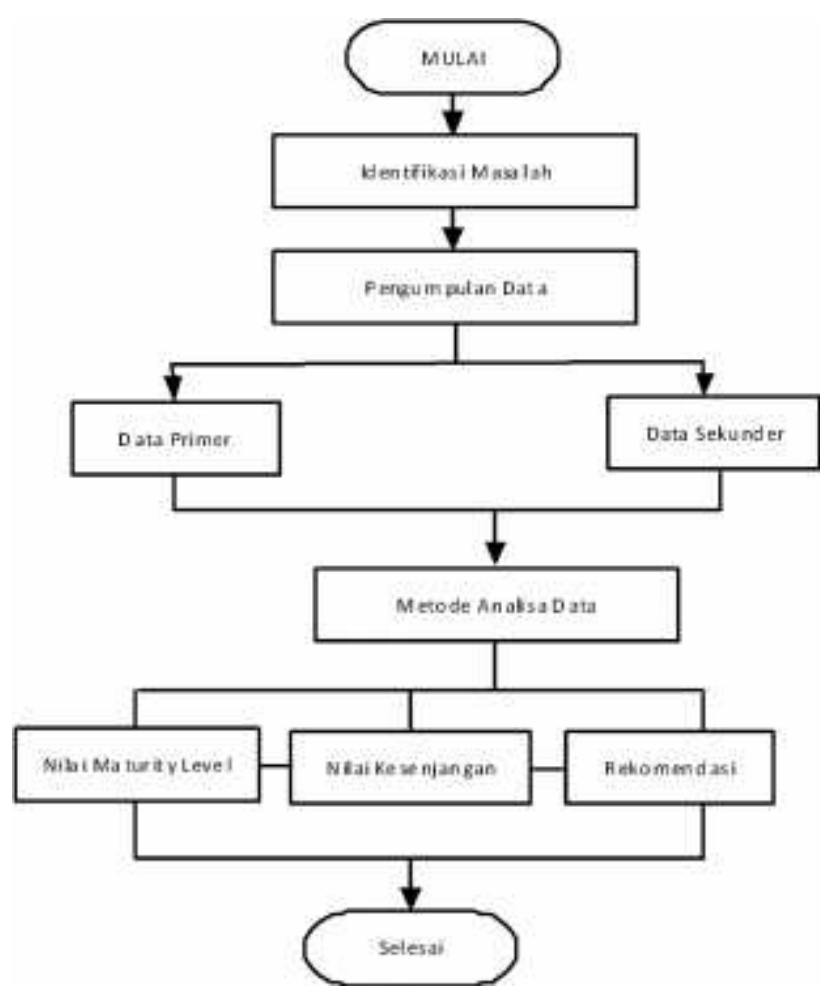

Gambar 1. Diagram Alir Penelitian

\section{HASIL DAN PEMBAHASAN}

Terdapat 7 proses dalam 3 domain yang digunakan dalam tujuan bisnis Pencapaian optimasi biaya dari penyampaian layanan meliputi empat tujuan bisnis yang diuraikan pada Tabel 1.[5]

Tabel 1. Pemetaan tujuan bisnis untuk tujuan bisnis ke proses-proses

\begin{tabular}{|c|c|c|}
\hline $\begin{array}{l}\text { Tujuan } \\
\text { Bisnis }\end{array}$ & Tujuan IT & Prosess \\
\hline \multirow{4}{*}{$\begin{array}{l}\text { Pencapaian } \\
\text { optimasi } \\
\text { biaya dari } \\
\text { penyampaian } \\
\text { layanan }\end{array}$} & $\begin{array}{l}\text { Perolehan dan pemeliharaan sistem aplikasi yang } \\
\text { standar dan terintegrasi }\end{array}$ & PO2,AI2,AI5 \\
\hline & $\begin{array}{l}\text { Perolehan dan pemeliharaan infrastruktur teknologi } \\
\text { informasi yang strandar dan terintegrasi. }\end{array}$ & $\mathrm{AI} 3$ \\
\hline & $\begin{array}{l}\text { Jaminan akan kepuasan yang saling menguntungkan } \\
\text { dengan pihak ketiga. }\end{array}$ & DS2 \\
\hline & $\begin{array}{l}\text { Peningkatan terhadap efisiensi biaya teknologi informasi } \\
\text { dan kontribusinya terhadap keuntungan bisnis }\end{array}$ & PO5,DS6 \\
\hline
\end{tabular}

\subsection{Analisa Tingkat kematangan}

Berdasarkan hasil data quisioner yang diolah untuk memperoleh maturity level saat ini (as-is) untuk domain dilakukan penilaian terhadap masing-masing ativitas. Untuk jawaban quisioner maturity level akan tersedia 6 jawaban dengan nilai 0-5. Nilai diperoleh dari perhitungan total pilihan jawaban kuisioner dikalikan dengan bobot dan dibagi dengan jumlah responden seperti pada rumus persamaan 1 


\section{indeks $k$ emator gan $=\frac{\left.\sum \text { (nilai maturit) level tian responden }\right)}{\text { Jumiah Responden }}$}

\subsection{Anlisa Kesenjangan (GAP)}

Tingkat kesenjangan diperoleh sesuai persamaan yaitu tingkat kematangan yang diharapkan dikurangi dengan tingkat kematangan saat ini pada rumus persamaan 2

$$
\text { nilai kesenjangan }=\mathrm{x}-\mathrm{y}
$$

$\mathrm{X}=$ tingkat kematangan yang diharapkan (to be)

$\mathrm{Y}=$ tingkat kematangan saat ini (as is)

\subsection{Mengolah Kuisioner}

Menyusun kuisioner dari setiap domain proses yang dilakukan pada tata kelola IT, Kuisioner dibuat sesuai dengan Maturity Model level 0 sampai level 5 berdasarkan jumlah pertanyaan dituangkan dalam tabel. Dengan tingkat persetujuan dan nilai terdiri dari tidak setuju $=0$, kurang setuju $=0,33$, Setuju $=0,66$, sangat setuju $=1$. Setiap pertanyaan dijawab dengan $\mathrm{X}$. Berikut contoh pada tabel 2 .

Tabel 2. Contoh Tabel Kuisioner

\begin{tabular}{|c|c|c|c|c|c|c|}
\hline Level & \multicolumn{1}{|c|}{ Pernyataan } & $\begin{array}{c}\text { Tidak } \\
\text { Setuju }\end{array}$ & $\begin{array}{c}\text { Kurang } \\
\text { Setuju }\end{array}$ & Setuju & $\begin{array}{c}\text { Sangat } \\
\text { Setuju }\end{array}$ & Nilai \\
\hline \multirow{2}{*}{0} & $\begin{array}{l}\text { Manajemen mengakui } \\
\text { akan } \\
\text { arsitektur } \begin{array}{r}\text { kebutuhan } \\
\text { informasi }\end{array}\end{array}$ & $\mathrm{X}$ & & & \\
\cline { 2 - 7 } & \multicolumn{3}{|c|}{ Total } & & & 0.33 \\
\hline & & & & & & \\
\hline 5 & & & & & & \\
\hline
\end{tabular}

\subsection{Maturity level TI}

\subsubsection{Penetapan Skoring dan Status Penilaian}

Tingkat kematangan proses Teknologi Informasi dibagi menjadi 6 level, mulai dari tingkat kematangan 0 sampai dengan tingkat kematangan 5. Adapun tingkat kematangan proses IT diuraikan pada tabel 3 [6].

Tabel 3. Penetapan Skoring dan Status Penilaian

\begin{tabular}{|l|l|l|}
\hline No & Nilai & Keterangan \\
\hline 1 & 0.00 & Non -Existent O (None) \\
\hline 2 & 1.00 & 1 Initial / Ad Hoc \\
\hline 3 & 2.00 & 2 Repeatable but intuitive \\
\hline 4 & 3.00 & 3 Defined Process \\
\hline 5 & 4.00 & 4 Managed and Measurable (Set) \\
\hline 6 & 5.00 & 5 Optimized \\
\hline \multicolumn{3}{|c|}{ (Sumber: Pederiva, 2003: 2) } \\
\hline
\end{tabular}

\subsubsection{Standar Penilai Maturity Level}

Teknik pengukuran Maturity Level menggunakan beberapa statement (pernyataan) dimana setiap pernyataan dapat dinilai tingkat kepatutannya dengan menggunakan standar nilai, seperti pada Tabel 4 
Tabel 4. Standar Penilaian Maturity Level

\begin{tabular}{|l|l|}
\hline \multicolumn{2}{|c|}{ Complience Level Numeric Values } \\
\hline Agreement With Statement & Complience Value \\
\hline Not at all & 0 \\
\hline A Little & 0,33 \\
\hline Quite a lot & 0,66 \\
\hline Completely & 1 \\
\hline
\end{tabular}

\subsection{Penentuan Obyek Proses Domain}

Semua domain dalam cobit 4.1 meliputi proses rincian sebagai berikut:

\section{1) Plan and Oganise (PO)}

Membahas tentang strategi, taktik, dan pengidentifikasian teknologi informasi dalam mendukung tercapainya tujuan bisnis. Domain proses PO terdapat 2 proses IT seperti terlihat pada tabel 5 .

Tabel 5. Tabel Plan and Oganise (PO)

\begin{tabular}{|l|l|}
\hline \multicolumn{1}{|c|}{ Prose IT } & \multicolumn{1}{c|}{ Keterangan } \\
\hline PO2 & Mendefinisikan arsitektur informasi \\
\hline P05 & Mengelola investasi TI \\
\hline
\end{tabular}

\section{2) Acquire and Implement (AI)}

Pada domain Acquire and Implement teknologi informasi diidentifikasikan, dikembangkan, diimplementasikan dan diintegrasikan kedalam proses bisnis. Domain AI ini terdapat dari dua proses teknologi informasi seperti terlihat pada tabel 6 .

Tabel 6. Acquire and Implement (AI)

\begin{tabular}{|l|l|}
\hline \multicolumn{1}{|c|}{ Prose IT } & \multicolumn{1}{|c|}{ Keterangan } \\
\hline AI2 & Memperoleh dan memelihara software aplikasi \\
\hline AI3 & Memperoleh dan memelihara infrastruktur teknologi \\
\hline AI5 & Memenuhi sumber daya TI \\
\hline
\end{tabular}

\section{3) Deliver and Support (DS)}

Domain ini untuk penyampaian dan layanan teknologi informasi mencakup dukungan dan layanan teknologi informasi pada bisnis, mulai dari penanganan keamanan dan kesinambungan, dukungan bagi pengguna serta manajemen data. Domain DS ini terdapat 2 proses teknologi informasi seperti terlihat pada tabel 7 .

Tabel 7. Deliver and Support (DS)

\begin{tabular}{|l|l|}
\hline \multicolumn{1}{|c|}{ Prose IT } & \multicolumn{1}{c|}{ Keterangan } \\
\hline DS2 & Mengelola layanan pihak ketiga \\
\hline DS6 & Mengidentifikasikan dan mengalokasikan biaya \\
\hline
\end{tabular}

3.6 Metode Analisa Data

3.6.1 Nilai Maturity level setiap domain

a. Plan and Oganise (PO)

Tabel 8. Plan and Oganise (PO) Maturity Level

\begin{tabular}{|c|c|c|}
\hline Prose IT & Keterangan & Maturity Level \\
\hline PO2 & Mendefinisikan arsitektur informasi & 3.0 \\
\hline P05 & Mengelola investasi TI & 2.5 \\
\hline \multicolumn{2}{|c|}{ Rata-Rata } & 2.75 \\
\hline
\end{tabular}


b. Acquire and Implement (AI)

Tabel 9. Acquire and Implement (AI) Maturity Level

\begin{tabular}{|l|l|c|}
\hline Prose IT & \multicolumn{1}{|c|}{ Keterangan } & Maturity Level \\
\hline AI2 & Memperoleh dan memelihara software aplikasi & 2.3 \\
\hline AI3 & Memperoleh dan memelihara infrastruktur teknologi & 2.4 \\
\hline AI5 & Memenuhi sumber daya TI & 2.8 \\
\hline \multicolumn{2}{|c|}{ Rata-Rata } & 2.5 \\
\hline
\end{tabular}

c. Deliver and Support (DS)

Tabel 10. Deliver and Support (DS)Maturity Level

\begin{tabular}{|l|l|c|}
\hline \multicolumn{1}{|c|}{ Prose IT } & \multicolumn{1}{|c|}{ Keterangan } & Matruity Level \\
\hline DS2 & Mengelola layanan pihak ketiga & 2.2 \\
\hline DS6 & Mengidentifikasikan dan mengalokasikan biaya & 2.4 \\
\hline Rata-Rata & & 2.3 \\
\hline
\end{tabular}

d. Hasil Perhitungan maturity level seluruh setiap proses dalam Control Objective TI

Tabel 11. Hasil Perhitungan Tingkat Kematangan seluruh Control Objective TI

\begin{tabular}{|c|c|l|c|}
\hline No & Proses IT & \multicolumn{1}{|c|}{ Keterangan } & $\begin{array}{c}\text { Nilai } \\
\text { Kematangan }\end{array}$ \\
\hline 1 & PO2 & Mendefinisikan arsitektur informasi & 3.0 \\
\hline 2 & P05 & Mengelola investasi TI & 2.5 \\
\hline 3 & AI2 & Memperoleh dan memelihara software aplikasi & 2.3 \\
\hline 4 & AI3 & Memperoleh dan memelihara infrastruktur teknologi & 2.4 \\
\hline 5 & AI5 & Memenuhi sumber daya TI & 2.8 \\
\hline 6 & DS2 & Mengelola layanan pihak ketiga & 2.2 \\
\hline 7 & DS6 & Mengidentifikasikan dan mengalokasikan biaya & 2.4 \\
\hline
\end{tabular}

e. Hasil Pengukuran maturity level dalam hasil control objective TI

Tabel 12. Hasil pengukuran maturity level Control Objective TI

\begin{tabular}{|l|l|c|}
\hline Prose IT & \multicolumn{1}{|c|}{ Keterangan } & Matruity Level \\
\hline PO & Plan and Oganise (PO) & 2.75 \\
\hline AI & Acquire and Implement (AI) & 2.5 \\
\hline DS & Deliver and Support (DS) & 2.3 \\
\hline Rata-Rata & & 2.51 \\
\hline
\end{tabular}

Dari tabel 12 menunjukan bahwa Plan and Oganise (PO) rata-rata nilia maturity level sebesar 2.75 hal ini menunjukan bahwa proses Plan and Oganise (PO) telah mencapai level Repeatable but intuitive, Acquire and Implement (AI) rata-rata nilai maturity level sebesar 2.5 menunjukan bahwa hasil mecapai Repeatable but intuitive dan Deliver and Support (DS) ratarata nilai maturity level sebesar 2.3 Repeatable but intuitive.

3.6.2 Kesenjangan antara Tingkat Kematangan Saat Ini dengan yang diharapkan.

Tabel 13. Kesenjangan antara Tingkat Kematangan Saat Ini dengan yang diharapkan.

\begin{tabular}{|c|c|c|l|}
\hline \multirow{2}{*}{$\begin{array}{c}\text { Proses } \\
\text { IT }\end{array}$} & $\begin{array}{c}\text { Kematangan } \\
\text { Saat ini (as-is) }\end{array}$ & $\begin{array}{c}\text { Kematangan } \\
\text { diharapkan (to-be) }\end{array}$ & $\begin{array}{l}\text { GAP (Kematangan diharapkan } \\
\text { be)-Kematangan Saat ini (as-is) }\end{array}$ \\
\hline
\end{tabular}




\begin{tabular}{|c|l|l|l|}
\hline PO2 & 3.0 & 3 & $4-3=1$ \\
\hline P05 & 2.5 & 3 & $4-3=1$ \\
\hline AI2 & 2.3 & 2 & $3-2=1$ \\
\hline AI3 & 2.4 & 2 & $3-2=1$ \\
\hline AI5 & 2.8 & 3 & $4-3=1$ \\
\hline DS2 & 2.2 & 2 & $3-2=1$ \\
\hline DS6 & 2.4 & 2 & $3-2=1$ \\
\hline \multicolumn{2}{|c|}{ Rata-Rata } & $7 / 7=1$ \\
\hline
\end{tabular}

Dari tabel 11 diatas tingkat kematangan seluruh control objective IT kondisi saat ini dan yang diharapkan dapat disajikan dalam bentuk gambar grafik dibawah ini:

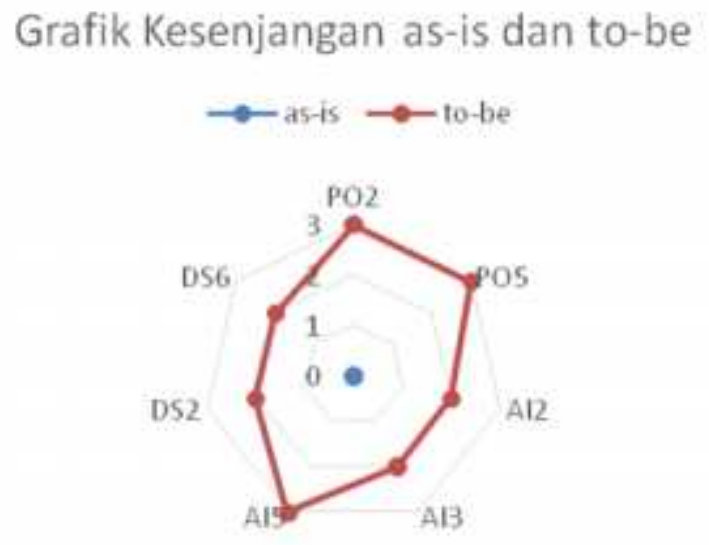

Gambar 2. Grafik kesenjangan as-is dan to-be

\subsubsection{Rekomendasi}

Rekomendasi pada 7 Proses TI untuk perbaikan dan peningkatan. Hal ini dilakukan agar terjadi peningkatan nilai pada pengukuran maturity level berikutnya. Secarau mum, rekomendasi yang diberikan adalah pembuatan SOP dan mendokumentasikan semua kegiatan kerja. Rincian rekomendasi untuk masing-masing Proses TI yang memiliki nilai kurang dari 3 adalah sebagai berikut:

a. PO5, mengelola investasi TI dengan membuat anggaran sesuai arah kebijakan pengembangan TI dan didokumentasikan

b. AI2, memberikan pemahaman dan kesadaran dalam memelihara perangkat lunak

c. AI3, melakukan konsistensi antara pendekatan taktis ketika memperoleh dan memelihara infrastruktur IT. Pemeliharaan didasarkan pada strategi yang telah ditetapkan dan mempertimbangkan kebutuhan aplikasi bisnis.

d. AI5, membuat kebijakan dasar dan prosedur yang terintegrasi dengan proses pengadaan TI.

e. DS2, memperbaiki dan melengkapi fasilitas IT untuk memuaskan pelayanan pelanggan

f. DS6, penyedian biaya untuk kebutuhan layanan informasi

\section{KESIMPULAN}

Hasil pengukuran maturity level berdasarkan optimasi pelayanan akademik pada Perguruan Tinggi Stimikom Stella Maris Sumba memberikan nilai maturity level 2.51. Nilai maturity level tersebut dapat dikategorikan pada level 2 Repeatable but intuitive Hal ini menunjukkan masih ada pembenahan yang harus diselesaikan terutama proses IT PO5,AI2,AI3,AI5,DS2 dan DS6 
belum terorganisir. Bidang Akademik sudah melakukan tugas dan wewenang sesuai dengan tugas pokok dan SOP (Standart Operating Procedure)

\section{SARAN}

Dari penlitian ini penulis memberikan beberapa saran yang nantinya dapat dilakukan oleh lembaga perguruan tinggi Stimikom Stella Mars Sumba antara lain:

a. Memperbaiki optimasi pelayanan sesuai dengan temuan yang direkomendasikan

b. Pihak pengelola manajemen lebih serius memperhatikan kebutuhan-kebutuahn BAAK dan setiap semester melakukan evaluasi untuk mengetahui seberapa tingkat optimasi pelayanan.

\section{UCAPAN TERIMA KASIH}

Puji Syukur Panjatkan Kehadirat Yang Maha Kuasa karena atas Berkat dan Karunia-Nya sehingga peneliti dapat menyelesaikan penelitian dengan baik. Pada kesempatan ini manyampaikan ucapan terima kasih kepada:

1. Bapak Drs Alexander Adis,MM Selaku Ketua Stimikom Stella Maris Sumba

2. Bapak Gregorius Kopong Pati,S.Kom,M.Kom Selaku Pembantu Ketua I

3. Ibu Cecilia Binti Gabriel S.Kom,M.Kom Selaku Kepala BAAK

4. Ibu Dr.Kusrini,M.Kom Selaku Pembimbing I yang telah meluangkan waktu untuk memberikan bimbingan sampai selesai

5. Bapak Henderi, M.Kom Selaku Pembimbing II yang telah meluangkan waktu untuk memberikan bimbingan sampai selesai

\section{DAFTAR PUSTAKA}

[1] Herlambang,S, dan Tanuwijaya, H,2005, Sistem Informasi Konsep Teknologi Rfid Di Perpustakaan Nasional RI Berdasarkan Framework COBIT 4.1 Pascasarjana IPB.

[2] Wire Bagye,2016.”Analisis Tingkat Kematangan Sistem Informasi Akademik Menggunakan Framework COBIT 4.1".Journal Speed - Sentra Penelitian Engineering dan Edukasi 2016, Volume 8 No 1 - 2016 - speed.web.id, ISSN : 1979-9330 (Print) 2088-0154 (Online)

[3] Awalludiyah Ambarwati, Ade Putra Habibi,2017." Analisis Maturity Level Business Goals 8 Menggunakan COBIT Pada PT. APLIN"Jurnal INTENSIF, Vol.1 No.2 Agustus 2017, ISSN: 2580-409X (Cetak) / 2549-6824 (Online)

[4] Khairan Marzuki,Arief Setyanto,Asro Nasiri,2018."Audit Tata Kelola Teknologi Informasi Menggunakan Cobit 4.1 Domain Monitoring Evaluasi Pada Perguruan Tinggi Swasta”.Seminar Nasional Sistem Informasi dan Teknologi Informasi 2018 (SENSITEK 2018),STMIK Pontianak, 12 Juli 2018,ISSN:2621-0428

[5] COBIT Steering Committee and the IT Governance Institute, COBIT framework, IT Governance Institute, Illinois, USA, 2000

[6] By Andrea Pederiva,2003,The COBIT Maturity Model in a Vendor Evaluation Case, Volume 3, 2003, infromation Systems control journal 